\title{
Mycological Studies in Cultural Heritage
}

Author links open overlay panelAna C.PinheiroSílviaSequeira

Show more

Share

Cite

https://doi.org/10.1016/B978-0-12-809633-8.21003-0Get rights and content

\section{Abstract}

Biodeterioration by fungi is a serious problem and is responsible for severe chemical and physical damage on virtually all supports used to create cultural heritage. The defacing and eventual loss of reading and aesthetic value urges those responsible to prevent fungal contamination altogether, diminish its impact or recover the damaged artefacts. The present Chapter focuses on the action fungi can have on some of our most precious cultural heritage collections (paper-based documents, photography and film, stone and ceramic glazes) and offers an insight on the current prevention, treatment and assessment strategies used in mycological studies in cultural heritage.

\section{Keywords}

Art

Biodeterioration

Ceramics

Conservation

Culture

Fungi

Heritage

Paper

Photography 
Prevention

Stone

Tiles

Treatment 